\title{
RESULTADOS Y PERSPECTIVAS DE LA CONGERVACIÓN IN VITRO DE RECURSOS FITOCENÉTICOS EN LA REGIÓN ORIENTAL DE CUBA
}

\section{Juan J. Silva, Ángel Espinosa, Leonardo Acosta, Orlando González, Ricardo Licea y Silvio Meneses}

Centro de Estudios de Biotecnología Vegetal

Universidad de Granma. Cuba

\section{INTRODUCCIÓN}

La agricultura moderna al poner énfasis en el logro de mayores producciones, ha originado la sustitución de las variedades locales por monocultivos que por su mayor productividad son ampliamente utilizados. Esto ha supuesto una drástica disminución de la variabilidad genética (erosión genética) presente en los agrosistemas que, además de afectar a su estabilidad, ha conllevado la pérdida de recursos genéticos esenciales para la obtención de nuevas variedades.

El acelerado deterioro de la biodiversidad ha provocado en los últimos años el interés y la ocupación de la mayoría de los países y de muchas organizaciones internacionales. En la Cumbre del Mundo celebrada en Brasil, esto fue ampliamente discutido y se adoptaron medidas que van al rescate y conservación de la biodiversidad. Entre estas medidas figuran la aplicación de métodos para la conservación del germoplasma tanto in situ como ex situ; destacándose, dentro de estos últimos, los métodos de conservación in vitro, los cuales permiten mantener el material libre del ataque de plagas y enfermedades, sin riesgo de pérdida por desastres naturales, ocupando el espacio mínimo y fácilmente disponible para su caracterización, multiplicación e intercambio.

El cultivo in vitro implica la sustitución de las condiciones naturales por artificiales, con la ventaja de que la luz y la temperatura pueden ser controladas en un espacio reducido. En ocasiones para plantas de ciclo reproductivo corto, los intervalos y frecuencia de subcultivos son más cortos que los ciclos de la planta en el campo. Otras importantes ventajas es la posibilidad de mantener plantas libres de virus, con un alto índice de multiplicación, independientemente de las condiciones climáticas (Villalobos et al., 1991).

\section{RESULTADOS DE LA CONSERVACIÓN IN VITRO DE RECURSOS FITOGENÉTICOS}

En la región oriental de Cuba existen 15 instituciones que emplean las técnicas de cultivo de tejidos vegetales con fines de propagación masiva de plantas, el mejoramiento genético y la conservación in vitro. Una de estas instituciones es el Centro de Estudios de Biotecnología Vegetal de la Universidad de Granma, donde se investiga en la conservación in vitro de cacao (Theobroma cacao L.), ñame (Dioscorea sp.), boniato (Ipomoea batatas (L.) Lam) y en plantas medicinales. A continuación se presentan los avances en cada uno de los cultivos. 


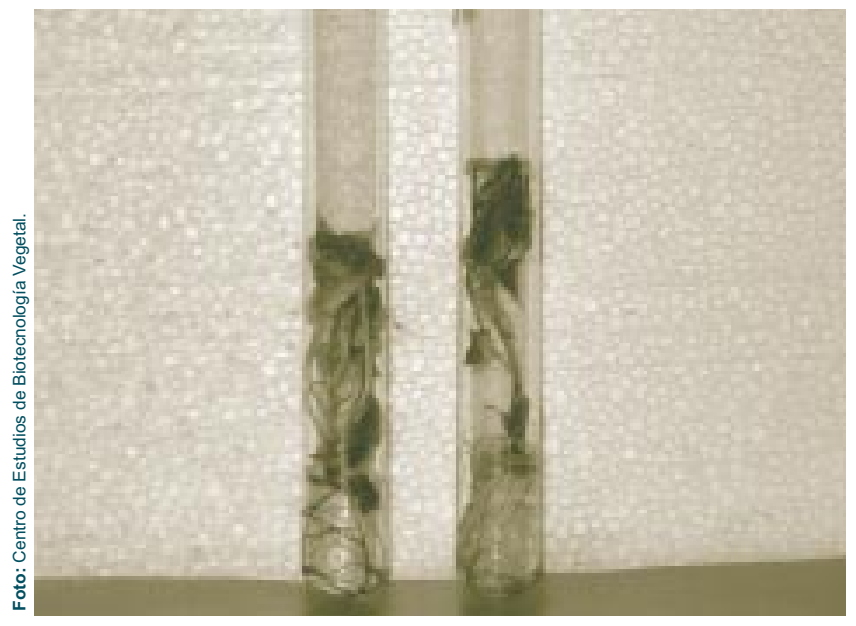

Foto 1: Plantas de boniato sometidas al programa de conservación in vitro.

\section{Cacoo}

El cacao (Theobroma cacao L.) ocupa un lugar importante dentro de las producciones agrícolas de muchos países de América Latina, África y Asia. En Cuba las principales plantaciones están ubicadas en cuatro provincias de la región Oriental: Guantánamo, Granma, Santiago de Cuba y Holguín, presentándose en la actualidad varios factores limitantes en cuanto al rendimiento: las afecciones por plagas y enfermedades y el bajo índice de multiplicación de los métodos tradicionales de propagación. En estudios realizados para la conservación in vitro de embriones cigóticos a corto plazo, se obtuvo la preservación de hasta 3 meses de los embriones, cuando estos fueron cultivados en el medio con las sales MS, suplementado con mio-inositol, sacarosa, manitol, agar y un $\mathrm{pH}$ de 5,7. Este método a corto plazo puede ser empleado en el intercambio internacional de germoplasma. En la foto 1 se muestran embriones en conservación. También se trabaja en el desarrollo de la embriogénesis somática en el cultivo, la cual puede ser empleada en la multiplicación de genotipos valiosos, el mejoramiento genético y la conservación in vitro. Se ha logrado la formación de embriones somáticos a partir de diferentes explantes como cotiledones, pétalos y estaminoides.

\section{Name}

La familia de las Dioscoreáceas agrupa seis géneros diferentes: Stenomeris, Avetra, Trichopus, Rajania, Tamus y Dioscorea. Desde el punto de vista de la alimentación humana, el más importante es el género Dioscorea, el cual comprende más de 600 especies e incluye todas las económicamente importantes. Actualmente, la especie asiática Dioscorea alata ocupa la mayor superficie cultivada en los trópicos, y le siguen en importancia D. cayenensis, D. bulbifera, D. trifida y D. esculenta. En el área del Caribe los clones introducidos pertenecen en su mayoría a la especie D. alata L. (Mantell et al., 1991). Este tubérculo tiene una amplia biodiversidad en la zona montañosa de la región oriental. En nuestro laboratorio se ha logrado establecer la multiplicación in vitro de diferentes clones, lo que constituye una vía para el rescate y recuperación del cultivo, muy deprimido en los últimos años. Estos resultados son muy importantes si tenemos en cuenta que alrededor del $40 \%$ del tubérculo se requiere para la propagación por métodos tradicionales. Borges (2000) desarrolló un método para la conservación por mínimo crecimiento empleando el manitol como inhibidor osmótico. Las plántulas fueron conservadas por nueve meses.

\section{Boniato}

El boniato (Ipomoea batatas (L.) Lam.), pertenece a la familia de las Convolvuláceas, siendo la única de esta familia que se cultiva comercialmente como alimento por poseer raíces comestibles, ocupando el sexto lugar entre los alimentos más importantes del mundo (Jarret, 1991). En Cuba el boniato se cultiva en casi todas las localidades, siendo un cultivo que se adapta fácilmente a las condiciones climáticas y de suelo, jugando un gran papel desde el punto de vista económico y para la alimentación humana. Constituye una fuente de carbohidratos, vitamina A y calcio, de ahí que se pueda considerar un alimento altamente energético; además, su follaje, rico en proteínas y minerales es un excelente alimento para animales. Actualmente las mayores dificultades que se afrontan en Cuba en este cultivo son básicamente: la lentitud y altos costos de los programas de mejoramiento genético convencionales, la disponibilidad y calidad de las semillas, así como los bajos rendimientos que se obtienen. La necesidad de satisfacer las demandas alimenticias de la población, ha exigido la búsqueda de alternativas 
para lograr la recuperación del cultivo del boniato. Una de ellas puede ser la aplicación de técnicas biotecnológicas, como una vía de producción de semillas libres de plagas y enfermedades, de mejoramiento genético y de recuperación y conservación de la diversidad genética del cultivo.

En el caso del boniato se han desarrollado diferentes técnicas de cultivo in vitro como la micropropagación por segmentos nodales, organogénesis indirecta a partir de hojas y la conservación in vitro por mínimo crecimiento de plántulas que se han mantenido durante un año con el empleo de medios de cultivo con manitol en cuatro clones (Foto 2), siendo la supervivencia superior al $70 \%$.

\section{Plantas medicinales}

En los últimos años ha tomado mucho auge en Cuba la medicina verde, debido a ello han surgido intereses en la propagación in vitro de especies como la caña santa (Cymbopogom citratus L.). En esta planta se ha establecido la micropropagación in vitro a partir de brotes axilares y la inducción de callos y regeneración de plantas.

\section{PERSPECTIVAS DE LA CONSERVACIÓN IN VITRO DE RECURSOS FITOGENÉTICOS EN LA REGIÓN ORIEN- TAL DE CUBA}

Existen dos vías fundamentales para la conservación in vitro de las plantas. La primera es la conservación a corto y mediano plazo con el empleo del mínimo crecimiento a través de la reducción de las sales minerales, la hipoxia o el uso de inhibidores osmóticos como el manitol, así como el empleo de bajas temperaturas. La tendencia de las investigaciones será hacia el perfeccionamiento de estas técnicas para los cultivos del cacao, ñame, boniato, $y$ plantas medicinales. Otras especies de plantas como el café, forestales y las cactáceas serán objeto de investigaciones de conservación in vitro en los próximos años. La segunda vía de conservación in vitro es la crioconservación en nitrógeno líquido. Esta técnica se ha iniciado su aplicación en el cacao, utili- zándose como explantes los embriones cigóticos, botones florales y callos.

La formación de recursos humanos especializados en las técnicas de conservación in vitro es una condición indispensable para alcanzar avances sustanciales en la aplicación de estos métodos. En estos momentos dos especialistas han completado su formación en Francia y España; otros han recibido el curso de crioconservación impartido durante la celebración del Congreso de Biotecnología en La Habana, REDBIO'98. Se trabaja en la búsqueda del financiamiento necesario para el establecimiento de un Laboratorio de Referencia en la Conservación in vitro de Germoplasma en la Región Oriental de Cuba.

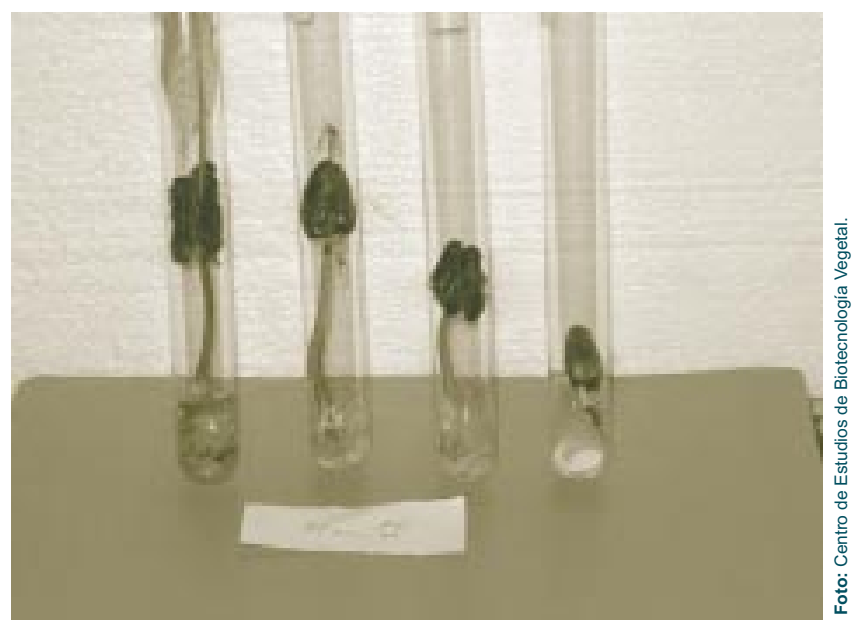

Foto 2: Embriones cigóticos de cacao obtenidos por técnicas de cultivo in vitro.

\section{BIBLIOGRAFIA}

Jarret, R. (1991). Cultivo de Tejidos de Camote. Publicaciones CIAT Colombia, 20 pp.

Borges, M. (2000). Conservación in vitro de ñame. Tesis de maestría. Universidad de Oriente, Santiago de Cuba. Cuba.

Mantell, S.H., S.Q. Haque, y F.L. Chandler (1991). Cultivo de tejidos y material de propagación libre de enfermedades en el ñame. En: W. Roca y L.A. Mroginski. Cultivo de Tejidos en la Agricultura. Fundamentos y Aplicaciones. CIAT, Colombia, pp.: 481-495.

Villalobos, V.M., P. Ferreira, y A. Mora (1991). The use of biotechnology in the conservation of tropical germplasm. Biotech. Adv. Vol 9, pp.: 127-215. 